\title{
Immediate Interpretation of FNA Smears From the Head and Neck Region
}

Torill Sauer, M.D., Atle Freng, M.D., and Per Djupesland, M.D.

FNA smears from 540 patients, investigated for visible and/or palpable lesions in the head and neck, examined immediately during consultation have been compared with the final cytologic diagnoses and, when possible, with histologic results. Preliminary and final cytologic diagnoses differed in 25 cases (4.6\%). Major discrepancies as to whether a lesion was benign or malignant occurred in 15 cases (2.8\%). Histologic follow-up was available for 188 lesions (35\%). There were 5 false-positive (2.6\%) and 9 false-negative (4.7\%) diagnoses, giving a sensitivity of $90.6 \%$ and a specificity of $94.6 \%$. The main diagnostic problem was benign, reactive lymphadenitis versus malignant lymphoma, which was responsible for 11 of 14 erroneous cytologic diagnoses $(3$ falsepositive and 8 false-negative smears). Diagn Cytopathol 1992;8: 116-118. (c) 1992 Wiley-Liss, Inc.

Key Words: Fine-needle aspiration; Preliminary cytologic diagnoses; Head and neck tumors

FNA has shown to be a valuable tool in the diagnosis of tumors in the head and neck region. A great variety of lesions occur here: both benign and malignant, primary and metastatic. Evaluation of FNA smears from this region poses a great challenge to the cytopathologist, as virtually any type of lesion may be found.

On-the-spot interpretation of smears has been performed with good results in diagnosing tumors from several sites. Specificity has ranged from $97 \%$ to $100 \%$, while sensitivity has been reported at $71 \%$ (abdominal aspirates) to $96 \%$ (other sites). ${ }^{1-4}$ Though the major role of immediate assessment is to ensure the adequacy of the material, it may also offer the clinician a preliminary diagnosis of the lesion. The aim of this study was to see whether the preliminary diagnoses attained an accuracy level acceptable for direct intervention.

Received May 1, 1991. Accepted October 8, 1991

From the Departments of Pathology and ENT, Ullevaal Hospital, University of Oslo, Norway.

Address reprint requests to Torill Sauer, M.D., Department of Pathology, Ullevaal Hospital, N-0407 Oslo 4, Norway.

\section{Materials and Methods}

The study was comprised of all patients with visible and/ or palpable lesions in the head and neck region examined at the ENT department of Ullevaal University Hospital over a 2 -yr period. There were 540 aspirations taken from 248 men and 292 women, with an age range of 3 mo to $94 \mathrm{yr}$ (median age, $49 \mathrm{yr}$ ).

The aspirations where performed by the cytopathologist, and both air-dried and wet-fixed smears were made. One of the air-dried smears was stained with Diff-Quick stain. Microscopic examination followed directly, and a preliminary diagnosis was given to the accompanying clinician. If the material appeared to be inadequate, a repeat aspiration was performed. The remaining smears were stained with May-Grünwald-Giemsa or a Papanicolaou stain. If the preliminary interpretation indicated a diagnostic difficulty, additional smears were prepared. When necessary, special stains were performed. The final report reached the clinician within 3-4 days.

\section{Results}

The sites of the 540 aspirations are shown in Table I. In 38 cases the aspirated material was inadequate $(7 \%)$. The overall concordance of the preliminary and final diagnoses is shown in Table II.

The preliminary and final diagnoses differed in 25 cases (4.6\%). In 6 cases in which the rapidly stained smears were inadequate, the remaining smears contained sufficient material for diagnosis of a benign non-neoplastic lesion. Four macroscopic fatty lesions, preliminarily thought to be lipomas, were ultimately judged to be inadequate.

Major discrepancies were noted in 15 cases $(2.8 \%)$. In 9 aspirates originally called benign, the final cytologic diagnoses were uncertain benign/malignant in 6 cases and suspected malignancy in 3 ("suspicious"). These included 6 lymph-node aspirates and 3 epithelial lesions. 
Table I. Aspiration Sites

\begin{tabular}{lcc}
\hline Location & Number & $\%$ \\
\hline Salivary glands & 164 & 30.5 \\
Lymph nodes & 154 & 28.5 \\
Neck NOS & 119 & 22 \\
Thyroid gland & 57 & 10.5 \\
Other sites & 46 & 8 \\
\hline NOS $=$ not otherwise specified & &
\end{tabular}

Table II. Preliminary Versus Final Cytologic Diagnoses

\begin{tabular}{lcccc}
\hline \multirow{2}{*}{$\begin{array}{l}\text { Final cytol. } \\
\text { diagnoses }\end{array}$} & \multicolumn{4}{c}{ Preliminary cytologic diagnoses } \\
\cline { 2 - 5 } Inadequate & Benign & Suspicious & Malignant \\
Inadequate & 32 & 4 & & 1 \\
Benign & 6 & 387 & 5 & \\
Suspicious & & 9 & 12 & \\
Malignant & & & 5 & 71 \\
\hline
\end{tabular}

Five "suspicious" lesions were finally given benign diagnoses. These were aberrant thyroid tissue, benign lymphadenitis, granulation tissue, foreign-body reaction, and possible proliferating myositis.

In 1 case initially interpreted as malignant, the total amount of celis in all the smears was scant, and it was finally judged to be insufficient for diagnosis.

Histologic follow-up was available in 188 cases (35\%). A comparison between the preliminary cytologic diagnoses and the histology is shown in Table III. There were $5(2.6 \%)$ false-positive diagnoses (Table IV) and $9(4.7 \%)$ false-negative ones (Table V), giving a sensitivity of $90.6 \%$ and a specificity of $94.6 \%$ for the preliminary cytologic diagnoses when correlated with the histology.

\section{Discussion}

The immediate advantage of rapid examination of FNA smears is the possibility of instant re-aspiration if necessary. This assures a minimum of insufficient specimens, which in our material was $7 \%$. Others have reported from $3 \%$ to $21 \%$ inadequate smears from this region. ${ }^{2,5-8}$

The possibility of gaining additional material for special stains also enhances diagnostic accuracy. Preliminary examination may indicate what type(s) of tumor(s) is probable, and special stains may be adapted accordingly. In our material the main diagnostic problem was malignant lymphoma versus benign lymphadenopathy, which was responsible for 11 of 14 false diagnoses ( 3 false positives and 8 false negatives). This emphasizes the need for immunocytochemic investigation in primary lymph-node lesions. ${ }^{9}$ In addition, quite a number of tumors in the head and neck region are poorly differentiated and require histochemical and/or immunologic staining to obtain a specific diagnosis. ${ }^{10-12}$

A good correlation was demonstrated between the pri-
Table III. Preliminary Cytologic Diagnoses Versus Histology

\begin{tabular}{lcccc}
\hline & \multicolumn{4}{c}{ Preliminary cytologic diagnoses } \\
\cline { 2 - 5 } Histology & Inadequate & Benign & Suspicious & Malignant \\
\hline None & 36 & 306 & 4 & 6 \\
Benign & 2 & 85 & 4 & 1 \\
Borderline lesion & & 2 & & 1 \\
Malignant & & 7 & 22 & 64 \\
\hline
\end{tabular}

Table IV. False-Positive Diagnoses

\begin{tabular}{ll}
\hline $\begin{array}{l}\text { Preliminary } \\
\text { cytologic diagnoses }\end{array}$ & \multicolumn{1}{c}{ Histologic diagnoses } \\
\hline $\begin{array}{l}\text { Acinic-cell carcinoma } \\
\text { Suspected adenoid-cystic carc. }\end{array}$ & $\begin{array}{l}\text { Pleomorphic adenoma } \\
\text { Monomorphic (basal cell) } \\
\text { adenoma }\end{array}$ \\
$\begin{array}{l}\text { Suspected malignant lymphoma } \\
\text { Lymph-node aspirate uncertain } \\
\text { ben/mal (2) }\end{array}$ & Benign, reactive lymphadenitis \\
\hline
\end{tabular}

Table V. False-Negative Diagnoses

\begin{tabular}{lc}
\hline $\begin{array}{l}\text { Preliminary } \\
\text { cytologic diagnoses }\end{array}$ & Histology \\
\hline Pleomorphic adenoma (1) & $\begin{array}{c}\text { Pleomorphic adenoma with area } \\
\text { of carcinoma }\end{array}$ \\
$\begin{array}{c}\text { Benign, reactive lymphadenitis } \\
\text { (1) }\end{array}$ & $\begin{array}{c}\text { Suspected M. Hodgkin, not } \\
\text { diagnostic } \\
\text { Benign, reactive lymphadenitis } \\
\text { (7) }\end{array}$ \\
\hline
\end{tabular}

mary and final diagnoses. Discrepancies were noted in 25 cases. In 15 cases $(2.8 \%)$ there was disagreement as to whether the lesion was benign or malignant. None of these affected the patients adversely, however, as the patients were still under investigation and no treatment had been initiated.

The sensitivity and specificity were $90.6 \%$ and $94.6 \%$, respectively, which is comparable to the findings in previous series from the head and neck region. ${ }^{3,13}$ The number of false-negative and false-positive diagnoses (Table IV and $\mathrm{V}$ ) are also comparable to those found by others. ${ }^{5,7,8}$

Thus our preliminary diagnoses show the same accuracy as has been demonstrated in other series in which the FNA smears have been examined and diagnosed in the traditional manner. In the practical handling of the patients, valuable time may be saved if a plan of treatment can be instituted without further delay. If there is any doubt about the diagnosis, however, the cytopathologist should refrain from giving an immediate diagnosis and urge the clinician to wait for the final report.

\section{References}

1. Duguid HLD, Wood RAB, Irving AD, Preece PE, Cuschieri A. Needle aspiration of the breast with immediate reporting of material. Br Med J 1979;2:185-7. 


\section{SAUER ET AL.}

2. Pak HY, Yota S, Teplitz RL, Shaw SL, Werner JL. Rapid staining techniques employed in fine needle aspirations of the lung. Acta Cytol 1981;25:178-84.

3. Miller DA, Carrasco CH, Katz RL, Cramer FM, Wallace S, Charnsangavej $\mathrm{C}$. Fine needle aspiration biopsy: The role of immediate cytologic assessment. Am J Roentgenol 1986;147:155-8.

4. Silverman JF, Finley JL, O'Brian KF, Dabbs DJ, Park HK, Larkin EW, Norris HT. Diagnostic accuracy and role of immediate interpretation of fine needle aspiration biopsy specimens from various sites. Acta Cytol 1989;33:791-6.

5. Frable WJ, Frable MAS. Thin needle aspiration. The diagnosis of head and neck tumors revisited. Cancer 1979;43:1541-8.

6. Russ JE, Scanlon EF, Christ MA. Aspiration cytology of head and neck masses. Am J Surg 1979;136:342-7.

7. Thomsen J, Andreassen JC, Bangbo C. Fine-needle aspiration biopsy of tumors of head and neck. J Laryngol Otol 1973;87:1211-6.
8. Sismanis A, Merriam J, Yamaguchi K, Shapshay S, Strong MS. Diagnostic value of fine needle aspiration biopsy in neoplasms of the head and neck. Otolaryngol Head Neck Surg 1981;89:62-6.

9. Martin SE, Zhang H, Magyarosy E, Jaffe ES, Hsu S, Chu EW. Immunologic methods in cytology: Definitive diagnosis of nonHodgkin's lymphomas using immunologic markers for $T$ - and B-cells. Am J Clin Pathol 1984;82:666-73.

10. Domagala W, Weber $\mathrm{K}$, Osborn M. Differential diagnosis of lymph node aspirates by intermediate filament typing of tumor cells. Acta Cytol 1986;30:225-34.

11. Domagala W, Lubinski J, Weber K, Osborn M. Intermediate filament typing of tumor cells in fine needle aspirates by means of monoclonal antibodies. Acta Cytol 1986;30:214-24.

12. Chess Q, Hajdu SI. The role of immunoperoxidase staining in diagnostic cytology. Acta Cytol 1986;30:1-7.

13. Young JE, Archibald SD, Shier KJ. Needle aspiration cytologic biopsy in head and neck masses. Am J Surg 1981;142:484-9. 